MATEC Web of Conferences 44, 01056 (2016)

DOI: $10.1051 /$ matecconf/20164401056

(c) Owned by the authors, published by EDP Sciences, 2016

\title{
Hybrid Electric Vehicle Motor Power Operation Control Analysis
}

\author{
Min Wei ${ }^{1, a}$, Bing Li ${ }^{1}$ and Juan Wei ${ }^{2}$ \\ ${ }^{1}$ School of Electronic Engineering, Xi'an Shiyou University, 710065 xi'an, Peoples R China \\ ${ }^{2}$ School of Telecommunications Engineering, Xidian University, 710071 xi'an, Peoples R China
}

\begin{abstract}
The design of hybrid electric vehicle drive motor is based on the premise of meeting the electric requirement. As the power generation and the regenerative braking are in operation state, it can not charge the battery when the normal generating voltage of motor is lower than that of the battery. In view of the problem, the hybrid electric vehicle driving motor control system is designed. In this system, the boost operation of pulse-width modulation (PWM) method of half controlled rectifier is used to improve the power voltage, as the speed is the main measure of the feedback current and voltage. The fuzzy PID control strategy can optimize the frequency and duty cycle of PWM pulse width, and then with the generating efficiency is greatly improved. The power generation principle, control strategy and software implementation are analyzed in the paper, and its rationality is verified by experiments.
\end{abstract}

\section{Introduction}

Hybrid electric vehicle (HEV) is the mainstream of the development of electric vehicles as it combines many advantages of the traditional fuel vehicle and pure electric vehicle ${ }^{[1]}$ and the development of battery is the bottleneck issue. For China, which has a vast territory but has a slow popular in charging station, the development of HEV is the first choice.

At present, the investment of the parallel hybrid electric vehicle (PHEV) is much more than other forms at home and abroad ${ }^{[2]}$. PHEV ensures the coordination of the internal combustion power source and the electric power source, so it can achieve the best energy distribution. To achieve the purpose, the running car motor, as the electromotor and engine, is used. The engine is always operated in the optimal efficiency state point by Clipping Fill Valley effect of the motor. At the same time in the automobile braking process, even if the speed is low, it is hoped that the motor's power generation voltage is higher than the battery voltage, which can normally charge the battery. Therefore, the vehicle system can achieve the highest efficiency.

The rest of the paper is organized as follows. Section 1 presents a brief overview of the system composition of the motor. Section 2 describes the power operation control strategy. Section 3 shows the software implementation. Section 4 provides some result and test data. Section 5 is the conclusion.

\section{System composition}

\footnotetext{
$\overline{{ }^{a} \text { Corresponding author: weimin_pb } @ 163 . c o m}$
}

As the main control chip, DSP ${ }^{[3-4]}$ (TMS320F2812) is the core design of the motor digital system. It is the most powerful and the strongest real-time system, and its highspeed can achieve the complex control strategy and make the cost reduction. The stator of the magneto of the control system is connected with Y shape three-phase windings. The main power circuit is the three-phase inverter bridge composed of large IGBT power modules. The structure diagram of the system is shown in Fig.1.

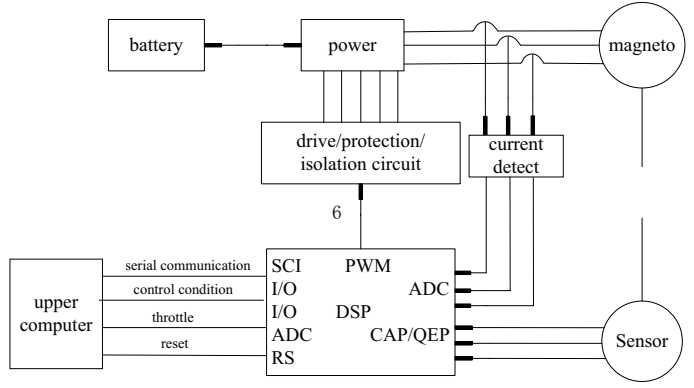

Figure 1. Structure diagram of system

\section{Power operation control analysis}

The design of the PHEV drive motor is to ensure that the output voltage of the maximum speed power is not greater than the battery rated voltage $\left(\mathrm{U}_{\mathrm{N}}\right)$, so that the electric energy can be outputted. The half bridge chopper principle is employed to control the generator, where three power tubes of the half bridge are closed by the main control panel signal and the other 3 power tubes are regularly controlled by the PWM. Thus, the boost voltage 
is produced. The signal waveform of the power operation control is shown in Fig. 2 .

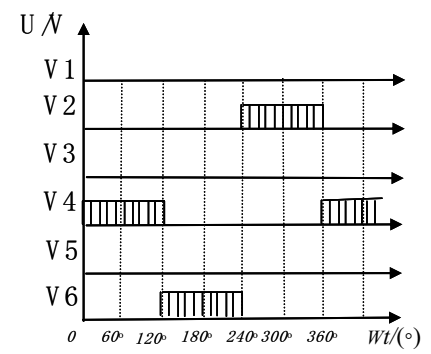

Fig.2 Signal waveform of power operation control

As shown in Fig.2, by using $\mathrm{V}_{4}$ during a PWM switch state period $(\mathrm{T})$ the voltage, current and energy of the power operation are analyzed, where the current waveform, the conducted and stopped power operation circuit are shown in Fig.3, Fig.4 and Fig.5, respectively.

In Fig.3, the circuit is in the storage state during the conducted circuit, as [ $\mathrm{t} 0, \mathrm{t} 1]$ shows, where t0 is equal to zero. The reason is that the loop current rises as the winding inductance saves the magnetic field energy in the period. The circuit is in the charging state during the stopped circuit, as [t1, t2] shows. The reason is that the loop current decreases as the winding inductance releases the magnetic field energy in the period.

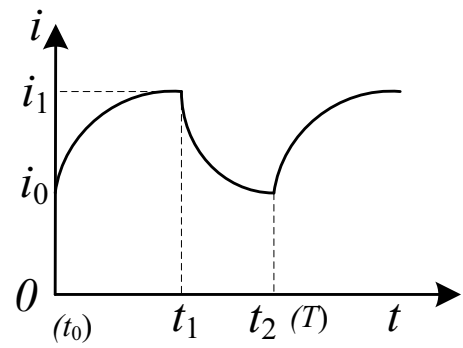

Fig.3 Current waveform in a PWM period

$\mathrm{V}_{4}$ is conducted during $[0, \mathrm{t} 1]$, and its circuit is described in Fig.4. When the pressure drop of $\mathrm{V}_{4}$ and $\mathrm{D}_{6}$ is ignored, $u_{\mathrm{A}}-u_{\mathrm{B}}=0$, and $i=i_{\mathrm{B}}=-i_{\mathrm{A}}$, the loop voltage is obtained as Eq. 1 shows.

$$
2(L-M) \frac{d i}{d t}+2 R i-\left(e_{A}-e_{B}\right)=0
$$

where $2(L-M)$ is the value of the motor inductance.

According to the three-factor method ${ }^{[5]}$, we obtain the Eq. 2 and the Eq.3.

$$
\begin{gathered}
i_{(\infty)}=\frac{e_{A}-e_{B}}{2 R} \\
\tau=\frac{L-M}{R}
\end{gathered}
$$

Setting $i_{(0+)}=i_{0}$, and combining with the Eq.2 and the Eq.3, the loop current is obtained as Eq.4.

$$
\begin{gathered}
i=\frac{e_{A}-e_{B}}{2 R}+\left(i_{0}-\frac{e_{A}-e_{B}}{2 R}\right) e^{-t R / L-M}, \\
0 \leq t \leq t_{1}
\end{gathered}
$$

The magnetic energy stored in the motor inductance can be representing as Eq.5.

$$
\begin{aligned}
W_{L} & =\int_{0}^{t_{1}} i u_{L} d t \\
& =\int_{0}^{t_{1}}\left(e_{A}-e_{B}-2 R i\right) i d t
\end{aligned}
$$

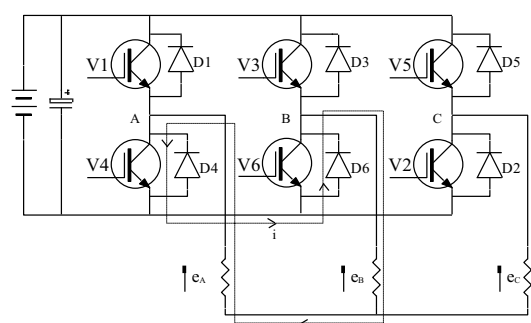

Fig.4 Conducted power operation circuit

$\mathrm{V}_{4}$ is stopped during [ $\left.\mathrm{t} 1, \mathrm{t} 2\right]$, and its circuit is described in Fig.5. When the pressure drop of $D_{1}$ and $D_{6}$ is ignored, $U_{d}=u_{\mathrm{A}}-u_{\mathrm{B}}$, and $i=i_{\mathrm{B}}=-i_{\mathrm{A}}$, the loop current is obtained as Eq.6.

$$
U_{d}=-2(L-M) \frac{d i}{d t}-2 R i+\left(e_{A}-e_{B}\right)
$$

According to the three-factor method, we obtain the Eq. 7 and the Eq.8.

$$
\begin{aligned}
i_{(\infty)} & =\frac{e_{A}-e_{B}-U_{d}}{2 R} \\
\tau & =\frac{L-M}{R}
\end{aligned}
$$

Setting $i_{(0+)}=i_{1}$, and combining with Eq.7 and Eq.8, the loop current is obtained as Eq.9 shows.

$$
\begin{aligned}
i= & \frac{e_{A}-e_{B}-U_{d}}{2 R} \\
& +\left(i_{0}-\frac{e_{A}-e_{B}-U_{d}}{2 R}\right) e^{-\left(t-t_{1}\right) R / L-M}, t_{1} \leq t \leq T
\end{aligned}
$$

The storage battery is representing as Eq.10 shows.

$$
\begin{aligned}
W_{d} & =\int_{t_{1}}^{T} u_{A B} i d t=\int_{t_{1}}^{T} U_{d} i d t \\
& =\int_{t_{1}}^{T}\left(e_{A}-e_{B}\right) i d t-\int_{t_{1}}^{T} 2 R i^{2} d t+\int_{t_{1}}^{T}\left(-u_{L} i\right) d t \\
& =W_{e}-W_{R}+W_{L}^{\prime}
\end{aligned}
$$

where $W_{L}^{\prime}$ is magnetic energy, which is equal to the energy by motor inductance released during [ $\mathrm{t} 1, \mathrm{t} 2(\mathrm{~T})]$.

Assuming that the energy stored in the motor inductance during $[0, \mathrm{t} 1]$ is equal to that released by the motor inductance during $[\mathrm{t} 1, \mathrm{~T}]$. Substituting the Eq.5 into the Eq.10, we obtain the Eq.11. 


$$
\begin{aligned}
W_{d}= & W_{e}-W_{R}+W_{L}^{\prime}=W_{e}-W_{R}+W_{L} \\
= & \int_{t_{1}}^{T}\left(e_{A}-e_{B}\right) i d t-\int_{t_{1}}^{T} 2 R i^{2} d t \\
& +\int_{0}^{t_{1}}\left(e_{A}-e_{B}-2 R i\right) i d t \\
= & \int_{0}^{T}\left(e_{A}-e_{B}-2 R i\right) i d t
\end{aligned}
$$

And then according to the Eq.11, we can obtain the Eq.12.

$$
\int_{t_{1}}^{T} u_{A B} i d t-=\int_{0}^{T}\left(e_{A}-e_{B}-2 R i\right) i d t
$$

Ignoring the impulse of the current (i) and the voltage $\left(u_{A B}\right)$, the Eq.13 can be obtained according to the Eq.12.

$$
u_{A B}=\frac{1}{1-\alpha}\left(e_{A}-e_{B}\right)
$$

where $\alpha$ is the PWM duty cycle and its value is equal to $t_{1} / T$.

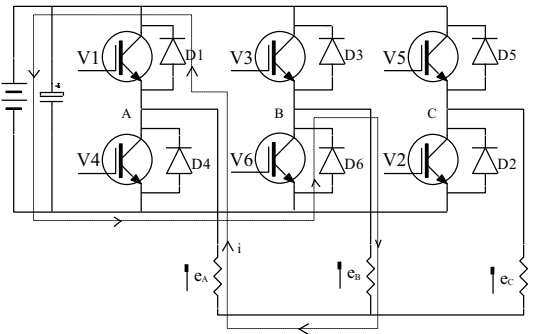

Fig.5 Stopped power operation circuit

\section{Software Implementation}

\subsection{Power operation mode}

In the case of the same system hardware, the power operation control is achieved by software and the mode is shown in Fig.6.

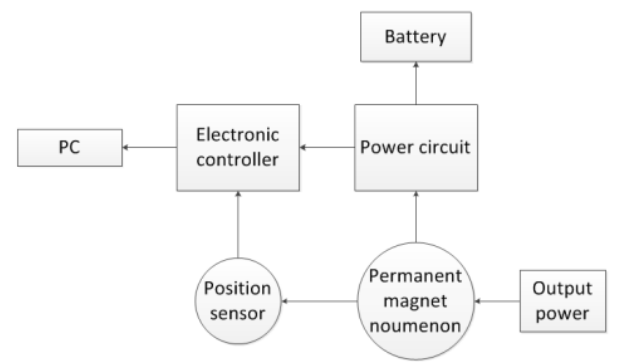

Fig.6. Power operation mode

\subsection{Power Operation Control Strategy}

The control system optimizes the frequency and duty cycle of the PWM pulse width by a fuzzy PID control strategy. The PID control algorithm is an incremental control algorithm. The PWM signal generates in the adjustment process of the voltage and current. And then the average value of voltage and current can be contained by adjusting the frequency and duty cycle $(\alpha)$ of PWM signal. When the voltage satisfies $u_{A B} \geq U_{d}$, the battery is charged, where $u_{A B}$ should be not greater than the maximum charging voltage of the battery and the current should be not greater than the maximum charging current of the battery.

The software of the power operation control employs a combination of the query and interruption. The core components of the software are the motor commutation, the generating voltage and the adjustment current, and they are completed by the capture interruption subroutine and $\mathrm{A} / \mathrm{D}$ converter interruption subroutine, respectively. The software flow chart of the power operation is described in the Fig.7.

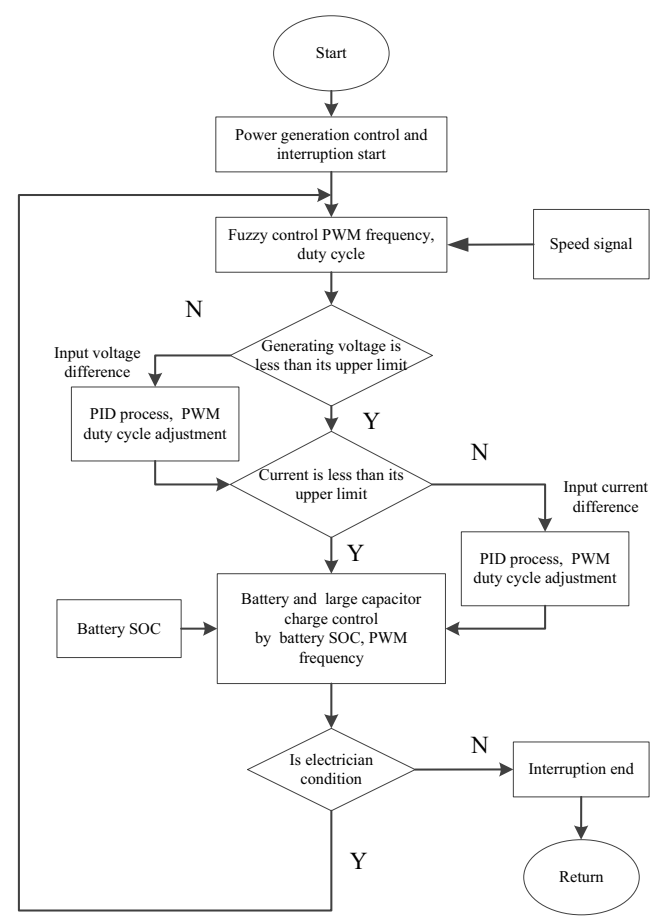

Fig.7. Software flow chart of power operation

\section{Experimental results}

Based on the HEV, a rare-earth permanent magnet brushless DC motor prototype is made by using the DSP control chip. The rationality of the motor is verified by debugging and testing the prototype. The result describes as follows.

(1) Rated voltage: $336 \mathrm{~V}$ (DC);

(2) Motor/generator power: $20 \mathrm{~kW} / 5 \mathrm{~kW}$;

(3) Motor weight ratio power: $1.37 \mathrm{~kW} / \mathrm{kg}$;

(4) Maximum motor speed: $5000 \mathrm{r} / \mathrm{min}$;

(5) System maximum efficiency: $89 \%$;

(6) Motor weight: $16.5 \mathrm{~kg}$;

(7) Controller Weight: $6.6 \mathrm{~kg}$

\section{Conclusions}

The result shows that the design for the control system based on TMS320F2812 is very feasible. The system 
provides a complete digital control scheme. In the case of the same motor structure and control circuit hardware, it ensures that the motor generates and operates, normally. Therefore, the system has a great reliability and security.

\section{Acknowledgments}

This study is supported by grants from the $\mathrm{Xi}$ 'an science and technology plan projects ( CXY1515(1)), Science and technology fund in shaanxi province department of education (2013JK1047), Xi'an Shiyou University Student Research Training Program(1027) and Shaanxi science and technology research and development projects (2012GY2-41).

\section{References}

1. C.H.Zhang, K.LI, etc., Shandong Univ. J. 41, 5(2011)

2. Y.H. Ge. Internal Combustion Engine Powerplant. 121,1(2011)

3. L.N.Duan, J.Zhao, Micromotors.47, 3 (2014)

4. Z.Y.Wang, E.Q.Chen,TMS320F2812 Principle and application of DSP(Electronic Industry Press, Beijing,2010)

5. Qin Zeng huang, Electrotechnics(higher education press, Beijing,2008) 